\title{
Virulence Diversity in Rhizoctonia Solani Causing Sheath Blight in RicePathogenicitya
}

\author{
Ramji Singh ${ }^{1}$, Shiw Murti², Mehilal ${ }^{3}$, Ajay Tomer ${ }^{4}$ and Durga Prasad \\ ${ }^{1}$ Department of Plant Pathology, SardarVallabhbhi Patel University of Agriculture \&Technology, Meerut-250110, Uttara Pradesh, India \\ ${ }^{2}$ Agriculture officer Oriental Bank of Commerce, India \\ ${ }^{3}$ Scientist CPRI, Meerut, India \\ ${ }^{4}$ Lovely Professional University Jalandhar Punjab, India, \\ ${ }^{5} \mathrm{MB}$ Agriculture College Saharsa, Bihar Agriculture University, Bihar, India
}

\begin{abstract}
Knowledge of variations in Rhizoctonia Solani causing rice sheath blight disease in different geographic regionsis still scarce and may be a useful tool for examining the nature and spread of population, disease epidemiology and host-pathogen interaction within rice patho-system. Molecular markers provide a basis for identifying patterns, dispersal and colonization in spatial and temporal distribution of pathogenic population and in development of species concepts by providing information about the limits of genetically isolated group in relation to patterns of morphological variation and behavior of any pathogen. Twenty-five isolates of Rhizoctonia Solani causing sheath blight in rice were collected from Kerala, New Delhi, Punjab, Uttarakhand and Uttar Pradesh of India and subjected for determination of virulence diversity. There was great diversity in the population of $R$. Solani which deferred greatly according to color and texture of colony, number and size of sclerotia, time taken for sclerotia formation and also the place and manner of sclerotia formation in the colony. At molecular level, also there was great diversity in the $R$. Solani population. A total of 80 PCR bands were detected among 25 isolates of $R$. Solani. The number of alleles per locus, varied from 1to7. Highest [1] PCR products were obtained with primers-OPW-13 and OPA-04 whereas lowest PCR products [2] were obtained with primer UBC-310 and OPB-08. There was only one monomorphic band, which was present in related primer UBC-373. The similarity coefficients among the $R$. Solani population ranged between 0.53 to 0.94 . One isolate of $R$. Solani from Uttar Pradesh (RS-16) and another isolate from Punjab (RS-1) were most distantly related. The $R$. Solani isolates (RS-11\&RS-12) and (RS-20\& RS-21) all belonging to Uttar Pradesh were genetically most closely to each other.
\end{abstract}

Keywords: Rhizoctonia Solani; Isolates; Virulence diversity; Sheath blight; PCR bands; Similarity coefficients; Alleles; Locus

\section{Introduction}

Sheath blight, caused by Rhizoctonia Solani Kuhn, earlier a minor disease, is now ranked second only tothe blast disease. The pathogen is regarded as an unspecialized with indefinite pathogenic races [3]. Attempts to control rice sheath blight have been dependent upon cultural practices, resistant cultivars, fungicides, and to some extent, biological methods. No resistant cultivar is available for practical use and the present intensive rice cultivation practices offer a favorable condition for sheath blight development. In addition, there is considerable pressure from environmental scientists to decrease emphasis on chemical control. However, the use of fungicides is unavoidable, but certainly, their use can be minimized as a long term solution to the crop health problem. Breeding for disease resistance may be most practical and feasible, but it could not be a final solution because of virulence diversity in the pathogenic population. Under thesecircumstances, management of sheath blight will require sharply focused approach including host resistance. Spray of fungicides and micronutrients at boot leaf and heading stage of rice plant has been resulted in controlling quite a few rice diseases and lead to significant increase in yield [4]. Management of this disease through host resistance will require a comprehensive knowledge of prevalent races of the target pathogen, which can be achieved by exploring the virulence diversity in the population of targeted pathogen.

The genetic difference underlying $R$. Solani population has provided an useful means of examining the nature and spread of population within rice Patho-system. Knowledge of variationsin the population of Rhizoctonia spp. causing rice sheath blight disease in different geographic regions is still scarce. Many problems associated with studying different level of diversity in Rhizoctonia are best addressed through the use of molecular markers, at the species level. Molecular markers aid in development of species concepts by providing information about the limits of genetically isolated group in relation to patterns of morphological variation and behavior. At the population level, molecular markers provide a basis for identifying patterns, dispersal and colonization in spatial and temporal distribution. The most convincing validation of Anastomosis group (AG) and inter specific group (ISG) concepts has come from molecular studies [5]. In view of these facts, investigation on virulence diversity of Rhizoctonia Solani causing sheath blight in rice were therefore undertaken.

\section{Materials and Methods}

\section{Sources and Maintenance of culture}

Twenty-five isolates of $R$. Solani were isolated and maintained. Of these, five isolates were obtained from Indian type culture Collection

*Corresponding author: Ramji Singh, Department of Plant Pathology, Sardar Vallabhbhi Patel University of Agriculture \&Technology, Meerut- 250110 (UP) India, Tel: 09451500541; E-mail: singh.ramji@gmail.com

Received August 03, 2015; Accepted August 13, 2015; Published August 20 2015

Citation: Singh R, Murti S, Mehilalm, Tomer A, Prasad D (2015) Virulence Diversity in Rhizoctonia Solani Causing Sheath Blight in Rice. J Plant Pathol Microb 6: 296. doi:10.4172/2157-7471.1000296

Copyright: (c) 2015 Singh R, et al. This is an open-access article distributed under the terms of the Creative Commons Attribution License, which permits unrestricted use, distribution, and reproduction in any medium, provided the original author and source are credited. 
(ITCC), IARI, New Delhi and remaining twenty isolates were collected from different parts of India (Table 1). Pathogen cultures were isolated from diseased leaf sheaths of infected rice plants on PDA media in petri plates and incubated at $28 \pm 1^{\circ} \mathrm{C}$ for 2-3 days. After three days of incubation, fine radiating mycelium growth were initiated form the edges of infected leaf bits. A small bit of actively growing mycelium was then transferred into the potato dextrose agar slants to obtain pure culture, which were further purified by germinating asingle sclerotium and maintained on PDA slants.Purity of $R$. Solani was ascertained by proving Koch's postulates after inoculating them on the highly susceptible cultivar, Pusa Basmati-1. Production of sheath blight symptoms by the respective isolates was taken as an indication of conformity of purity for the test fungus.

\section{Determination of cultural and morphological variability}

Cultural and Morphological variability were determined by taking observation on colony colour, growth pattern, and growth rate.The color of colony was determined with the help of munsel's Soil Color Chart (Munsell Color Company, Inc.1954). Growth pattern was recorded by visual observation according to growth of aerial hyphae. Growth rate of each isolate was measured, using plastic scale at the interval of $24 \mathrm{~h}, 48 \mathrm{~h}, 72 \mathrm{~h}$ and $96 \mathrm{~h}$.

\section{Determination of sclerotial characteristics}

Sclerotial characteristics viz, color, texture, number, size, time taken for initiation of sclerotia formation, pattern of production (central, peripheral and scattered) and location (Aerial-Sclerotia formed, on the aerial mycelium; Surface-Sclerotia formed on the surface mycelium; Embedded -Sclerotia formed on the substrate ) of sclerotia were recorded [6]. The diameter of the sclerotia was measured with the help of randomly harvested 20 sclerotia with the help of Digital Vernier Calipers (Mitutoyo Corp made in Japan). No sclerotia forming isolates were categourized as poor, 1-10 fair, 11-20 moderate, 21-40 good, 4160 very good and $>60$ as excellent.

\section{Molecular variability}

Preparation of genomic DNA: DNA extraction from mycelial mat of $R$. Solani grown on Potato Dextrose Broth (PDB) was done by CitimideTetradecylTrimethyl Ammonium Bromide (CTAB) methods [7]. DNA samples were further purified by taking a stock solution of RNase-A which was prepared @ $10 \mathrm{mg} / \mathrm{ml}$ in 10 mMTris- $\mathrm{HCl}$ (pH 8.0) and $15 \mathrm{mM}$ sodium chioride. The solution was boiled for 10 minutes to destroy DNase and allowed for cooling slowly at room temperature. From the stock, $2 \mu$ l, of RNase was added to the crude DNA samples and incubated at $37^{\circ} \mathrm{C}$ for one hour. DNA concentration of sample and purity was determined by taking ultraviolet absorbance at $260 \mathrm{~nm}$ and $280 \mathrm{~nm}$, in a spectrophotometer followed by agrose gel electrophoresis

Quantification of DNA was done by using Spectrophotometer (Nano Drop,NA-1000). One $\mu$ sterilized double distilled water was placed in Spectrophotometer and wiped with tissue paper and one $\mu$ of sample DNA was placed in spectrophotometer. Reading was taken at wavelengths of $260 \mathrm{~nm}$.Concentration of DNA varied (399.1-5085.2 ng) in different isolates of R. Solani. Working solutions having concentration of $25 \mathrm{ng} /$ $\mu \mathrm{l}$ were prepared for optimization of PCR reaction by Gel electrophoresis method by loading $7 \mu \mathrm{l}$ of mixture ( $5 \mu \mathrm{l} \mathrm{DNA}+2 \mu \mathrm{l}$ loading dye)of each isolates along with $1 \mathrm{~Kb}$ marker in 1.0 per centagrose gel.

Standardization of RAPD protocolandOptimization of Polymerase Chain Reaction (PCR): Composition of PCR reaction was optimized by varying concentration of different component of reaction mixture, which included template DNA (25 ng, $30 \mathrm{ng}, 50 \mathrm{ng}$, 75ng, 100ng), Taq DNA polymerase (0.5units, 1.0units, 1.5 units) and $\mathrm{MgCl}_{2}(0.4 \mathrm{mM}, 0.5 \mathrm{mM}, 0.6 \mathrm{mM})$. Different PCR profiles were tested for obtaining best amplification of nucleic acid of R.Solani isolates. The PCR reaction was performed in Bioneer thermal cycler programme. RAPD condition for $R$. Solani were standardized and final PCR composition was: $10 \mathrm{X}$ Taq buffer containing $15 \mathrm{mM} \mathrm{MgCl}_{2}(2.5 \mu \mathrm{l}) \mathrm{dNTP}$ mix (dATP, dGTP, dCTP, dTTP) $1.0 \mu \mathrm{l}$, primer $(0.4 \mu \mathrm{M}) 1.0 \mu \mathrm{l}$, Taq DNA polymerase $(3 \mathrm{U} / 1 \mu \mathrm{l}) 0.5 \mu \mathrm{l}$. Total reaction volume was made up to $25 \mu \mathrm{l}$ using sterile double distilled water. Different PCR profiles were tested for best amplification of DNA. The standardized temperature profiles of $94^{\circ} \mathrm{C}$ for 5 minutes followed by 38 cycles of $94^{\circ} \mathrm{C}$ of 1 minute, $36^{\circ} \mathrm{C}$ for 1 minute, $72^{\circ} \mathrm{C}$ for 2 minutes, with an elongation of $72^{\circ} \mathrm{C}$ for 10 minutes which gave best results hence, was used for DNA amplification [8]

Primer survey and selection: Preliminary primer screening was carried out with 25 primer (GCC Company limited) out of them, only 12 primer gave best amplification and each primer was testedwith two isolates for assessing amplification and was employed for molecular variation analysis (Table 2). The primer that gave reproducible and scorable amplification were further used in the analysis of genetic variability of the isolates.

Agarose gel electrophoresis: $2 \mu \mathrm{l}$ of loading dye was added to the $25 \mu \mathrm{l}$ of amplification products obtained after the PCR reaction, and loaded into individual wells of 1.2 per cent horizontal agarose gel in TAE buffer, pre-stained with Ethidium Bromide $(1 \mu \mathrm{g} / \mathrm{ml})$. Electrophoresis was carried out at 60 volts for $2 \mathrm{~h}$ in TAE buffer. One $\mathrm{Kb}$ ladder (MBI, Fermantas) was used as a marker. The gel was observed in a PerkinElmer Geliance 200 Imaging system.

\section{Scoring of RAPD-PCR amplification}

Each amplification product was considered as RAPD marker and was scored across all samples. Data was entered in a matrix in which

\begin{tabular}{|l|l|l|l|}
\hline Isolate code & Place of collection & State & Crop (Host) \\
\hline RS-1 & Ludhiana & Punjab & Rice \\
\hline RS-2 & Ludhiana & Punjab & Rice \\
\hline RS-3 & ITCC ,IARI & New Delhi & Rice \\
\hline RS-4 & ITCC,IARI & New Delhi & Rice \\
\hline RS-5 & ITCC,IARI & New Delhi & Rice \\
\hline RS-6 & ITCC,IARI & New Delhi & Urd bean \\
\hline RS-7 & ITCC,IARI & New Delhi & Maize \\
\hline RS-8 & Pattambi & Kerala & Rice \\
\hline RS-9 & Moncopu & Kerala & Rice \\
\hline RS-10 & Pant nagar & Uttarakhand & Rice \\
\hline RS-11 & Faizabad & Uttar Pradesh & Rice \\
\hline RS-12 & Faizabad & Uttar Pradesh & Moong bean \\
\hline RS-13 & Meerut & Uttar Pradesh & Rice (PB-1) \\
\hline RS-14 & Meerut & Uttar Pradesh & Rice (Masoori) \\
\hline RS-15 & Meerut & Uttar Pradesh & Rice \\
\hline RS-16 & Meerut & Uttar Pradesh & Rice (HKR-1) \\
\hline RS-17 & Meerut & Uttar Pradesh & Rice(PB-9) \\
\hline RS-18 & Meerut & Uttar Pradesh & Rice(Sungandha-5) \\
\hline RS-19 & Meerut & Uttar Pradesh & Rice(Sungandha-7) \\
\hline RS-20 & Meerut & Uttar Pradesh & Rice(PRH-10) \\
\hline RS-21 & Meerut & Uttar Pradesh & Rice(Pusa-677) \\
\hline RS-22 & Faizabad & Uttar Pradesh & Rice(ND-10) \\
\hline RS-23 & Meerut & Uttar Pradesh & Rice \\
\hline RS-24 & Ueerut & Potato \\
\hline RS-25 & & Rice(PR-53) \\
\hline & Tadadesh & \\
\hline
\end{tabular}

Table 1: List of Rhizoctonia solani isolates with their place of collection. 
all observed bands or characters state was listed. The RAPD pattern of each isolate was evaluated assigning character state to all bands that could be observed in gel with a particular primer. The characters state "1" was given if this band could reproducibly detect in all RAPD analysis with an isolate/primer combination. The character state " 0 " was assigned if band was lacking or it was not possible to determine its presence with certainty.

Molecular diversity analysis using Jaccard similarity coefficient: Similarity index matrix generated, based on proportion of common amplified band between two isolates [9] using $\mathrm{F}=(2 \mathrm{MxY}) /(\mathrm{Mx}+$ My) where, $\mathrm{F}$ is similarity index, $\mathrm{Mx}$ is the number of band in isolates $\mathrm{x}, \mathrm{My}$ is the number of band in isolate $\mathrm{y}$, and Mxy is the number of bands common to both $\mathrm{x}$ and $\mathrm{y}$. From the number of common bands in the fingerprint pattern on the two isolates, the formula of Nei\&Li [9] was used to calculate a similarity coefficient for pairs of isolates. Pair, which has a higher coefficient, is more closely related than those with a lower coefficient. In the construction of the matrix, it is assumed that corresponding bands arise by amplification of the same genetic locus. Similarity matrixes are very useful for showing relationship that is not apparent from the gel photograph. Cluster analysis of the data was made, based on the similarity indices between pathogen isolates, using NTSYSpc version 2.0 software [10] and a dendogram was constructed.

\section{Results}

\section{Cultural variability of Rhizoctonia Solani}

Colony colour: Out of twenty-five isolates, five isolates of (RS1, RS-2, RS-8, RS-21 and RS-25) Rhizoctonia Solani were of whitish brown color, seven isolates (Rs-3, RS-6, RS-13, RS-14, RS-15, RS-17 and RS-19) were of light brown color, six isolates (RS-5, RS-7, RS-10, RS-11, RS-16 and RS-23) were of yellowish brown color, four isolates (RS-4, RS-12, RS-20 and RS-24) were of dark brown color, two isolates (RS-18, RS-22) were of pale brown color, and one isolate (RS-9) was of milky browncolor (Table 3).

Growth pattern: Of the twenty-five isolates of Rhizoctonia Solani, six isolates (RS-2, RS-3, RS-7, RS-8, RS-11, RS-13) were found to be growing abundantly and accordingly categorized into thegroup-1. Thirteen isolates(RS-1, RS-5, RS-6, RS-9, RS-12, RS-14, RS-15, RS18 , RS-19, RS-20, RS-21, RS-22, RS-24) were found to be of moderate growth pattern and categorized into group-2, whereasremaining six isolates (RS-4, RS-10, RS-16, RS-17, RS-23, RS-25) were found to be of slightly low growth pattern hence categorized into group-3 (Table 3 ).

Growth rate: Among twenty five isolates, fast growing (>65 $\mathrm{mm}) 3$ isolates ( RS-3, RS-7and RS-17) were categorized in group-1, medium growing $(60-65 \mathrm{~mm}) 3$ isolates (RS- 8,RS-11, and RS-13) were categorized into group-2 and remaining nineteen isolates (40-59 $\mathrm{mm}$ ) i.e.RS-1,RS-2,RS-5,RS-6,RS-9,RS-10,RS11,RS12,RS-14,RS-15,RS16,RS-18,RS-19,RS-0,RS21,RS-22,RS-23,RS-24,RS-25 were categorized into group-3 (Table 3).

Colour of sclerotia: All twenty five isolates of Rhizoctonia Solani showed great variation in the colour of sclerotium (Table 5). Based on the pigmentation of the sclerotium, isolates were assigned into four groupsi.e. dark brown which included isolates RS-4, RS-7, RS-9, RS-11, RS-17, RS-18, RS-23, and RS-25, dark yellowish brown which included isolates RS-2, RS-5, RS-13, RS-16, RS-19, and RS-21, olive brown which included isolates RS-8, RS-10, RS-12, RS-14, RS-15, RS-20 and RS-22 and light brown which included isolates RS-1, RS-3 and RS-6. The isolate RS-24 did not bear any sclerotia.
Texture of sclerotia: Based on texture of sclerotia the isolates were classified into two groups i.e. smooth and rough (Table 5). Of all twenty five, ten isolates viz- RS-1, RS-2, RS-3, RS-8, RS-10, RS-12, RS-14, RS16,- RS-22 and RS-23 were having smooth category of sclerotium and remaining 14 isolates viz-RS-4, RS-5, RS-6, RS-7, RS-9, RS-11, RS13, RS-15, RS-17, RS-18, RS-19, RS-20, RS-21 and RS-25 were having rough categoryof sclerotium.

Number of sclerotia: Among the 25 isolates,no sclerotium was formed in isolates RS-24 and was categorized into group-1 (poor). None of the isolates was categorized into group-2 (fair) and group 3 moderate. Group-4 (good) included six isolates (RS-2, RS-8, RS-12, RS16 , RS-18 and RS-19), Group -5 (very good) included seven isolates (RS-4, RS-7, RS-9, RS-13, RS-17, RS-23 and RS-25) and group-6 (excellent) included eleven isolates (RS-1,RS 3,RS5,RS-6,RS-10, RS-11, RS-14, RS-15,RS-20, RS-21 and RS-22, ).

Diameter of sclerotia: Based on diameter of sclerotia, the isolates were categorized into two groups. Group -1 had diameter range form 1.21-1.75 mm and group -2 had diameter range from 1.75-2.94 mm. Diameter of the sclerotia was observed up to maximum range in isolates RS-17 $(2.94 \mathrm{~mm})$ and minimum in RS-1 $(1.24 \mathrm{~mm})$. Seven isolates (RS1,RS-2, RS-4, RS-10, RS-11,RS-16 and RS-19) were categorized into group-1 with diameter range between 1.21-1.75 mm. Seventeen isolates (RS-3, RS-5, RS-6, RS-7, RS-8, RS-9, RS-12, RS-13, RS-14, RS-15, RS17, RS-18, RS-20, RS-21, RS-22, RS-23 and RS-25) were categorized into group-2 (Table 4.4) having diameter range between 1.75-2.94 mm.

Location of sclerotia formation: The location of sclerotia was observed on the basis where actually the sclerotia were formed in the fungal colony (Table 4.5). Based on the location of sclerotia formation, these isolates were categorized into three groups. First group included those isolates where sclerotium formed within the aerial mycelium

\begin{tabular}{|c|c|c|}
\hline S. No. & Name of primers & Sequences \\
\hline 1. & OPA-01 & CAGGCCCTTC \\
\hline 2. & OPA-02 & TGCCGAGCTG \\
\hline 3. & OPA-03 & AGTCAGCCAC \\
\hline 4. & OPA-04 & AATCGGGCTG \\
\hline 5. & OPA-10 & GTGATCGCAG \\
\hline 6. & OPA-19 & CAAACGTCGG \\
\hline 7. & OPA-20 & GTTGCGATCC \\
\hline 8. & OPB-01 & CCGTCGGTAG \\
\hline 9. & OPB-08 & GTCCACACGG \\
\hline 10. & OPB-18 & CCACAGCAGT \\
\hline 11. & OPN-20 & CGTGCTCCGT \\
\hline 12. & OPU-02 & CTGAGGTCTC \\
\hline 13. & OPU-06 & ACCTTTGCGG \\
\hline 14. & OPU-14 & TGGGTCCCTC \\
\hline 15. & OPV-12 & АССССССАСТ \\
\hline 16. & OPV-20 & CAGCATGGTC \\
\hline 17. & OPW--13 & CACAGCGAACA \\
\hline 18. & UBC-220 & GTCGATGTCG \\
\hline 19. & UBC-248 & GAGTAAGCGG \\
\hline 20. & UBC-249 & GCATCTACCG \\
\hline 21. & UBC-310 & GAGCCAGAAG \\
\hline 22. & UBC-338 & CTGTGGCGGT \\
\hline 23. & UBC-373 & CTGAGGAGTC \\
\hline 24 & UBC-374 & GGTCAACCCT \\
\hline 25 & OPZ-20 & ACTTTGGCGG \\
\hline
\end{tabular}

Table 2: List of Primers used for survey of amplification. 
Citation: Singh R, Murti S, Mehilalm, Tomer A, Prasad D (2015) Virulence Diversity in Rhizoctonia Solani Causing Sheath Blight in Rice. J Plant Pathol Microb 6: 296. doi:10.4172/2157-7471.1000296

Page 4 of 8

\begin{tabular}{|c|c|c|c|c|c|c|c|c|c|}
\hline \multirow{2}{*}{ Isolates } & \multirow{2}{*}{ Colony colour } & \multicolumn{3}{|c|}{ Growth pattern } & \multicolumn{5}{|c|}{ Colony growth diameter $(\mathrm{mm})$ at different intervals } \\
\hline & & Abundant & Moderate & Slight & $24 \mathrm{~h}$ & $48 \mathrm{~h}$ & $72 \mathrm{~h}$ & $96 \mathrm{~h}$ & Mean \\
\hline RS-1 & White brown & - & + & - & 5.60 & 47.00 & 90.00 & 90.00 & 58.15 \\
\hline RS-2 & White brown & + & - & - & 8.60 & 35.00 & 67.33 & 90.00 & 50.23 \\
\hline RS-3 & Light brown & + & - & - & 30.00 & 90.00 & 90.00 & 90.00 & 75.00 \\
\hline RS-4 & Dark brown & - & - & + & 0.00 & 46.66 & 79.66 & 90.00 & 54.08 \\
\hline RS-5 & Yellowish brown & - & + & - & 0.00 & 33.33 & 85.66 & 90.00 & 52.25 \\
\hline RS-6 & Pale brown & - & + & - & 0.00 & 35.00 & 83.33 & 90.00 & 52.08 \\
\hline RS-7 & Yellowish brown & + & - & - & 28.30 & 66.33 & 90.00 & 90.00 & 68.66 \\
\hline RS-8 & White brown & + & - & - & 16.00 & 49.00 & 90.00 & 90.00 & 61.25 \\
\hline RS-9 & Milkish brown & - & + & - & 0.00 & 48.00 & 73.42 & 89.00 & 52.61 \\
\hline RS-10 & Yellowish brown & - & - & + & 0.00 & 55.33 & 89.00 & 90.00 & 58.58 \\
\hline RS-11 & Yellowish brown & + & - & - & 15.00 & 58.3 & 90.00 & 90.00 & 63.33 \\
\hline RS-12 & Dark brown & - & + & - & 0.00 & 37.66 & 90.00 & 90.00 & 54.42 \\
\hline RS-13 & Light brown & + & - & - & 16.00 & 59.00 & 90.00 & 90.00. & 63.75 \\
\hline RS-14 & Light Brown & - & + & - & 8.00 & 41.00 & 81.00 & 90.00 & 55.00 \\
\hline RS-15 & Cream brown & - & + & - & 6.00 & 39.66 & 84.46 & 90.00 & 55.03 \\
\hline RS-16 & Yellowish brown & - & - & + & 0.00 & 19.00 & 51.33 & 90.00 & 40.08 \\
\hline RS-17 & Pale brown & - & - & + & 25.00 & 60.00 & 90.00 & 90.00 & 66.25 \\
\hline RS-18 & Pale brown & - & + & - & 0.00 & 16.33 & 56.33 & 90.00 & 40.67 \\
\hline RS-19 & Light brown & - & + & - & 0.00 & 24.31 & 68.34 & 90.00 & 45.66 \\
\hline RS-20 & Dark brown & - & + & - & 0.00 & 27.00 & 80.33 & 90.00 & 49.33 \\
\hline RS-21 & White brown & - & + & - & 0.00 & 43.35 & 90.00 & 90.00 & 55.84 \\
\hline RS-22 & Pale brown & - & + & - & 0.00 & 43.00 & 75.00 & 90.00 & 52.00 \\
\hline RS- 23 & Yellowish brown & - & - & +- & 0.00 & 60.00 & 86.66 & 90.00 & 59.17 \\
\hline RS-24 & Dark brown & - & + & - & 18.00 & 22.10 & 44.33 & 90.00 & 43.61 \\
\hline RS-25 & White brown & - & - & + & 0.00 & 6.33 & 61.00 & 78.60 & 36.48 \\
\hline
\end{tabular}

Table 3: Cultural characteristics of different isolates of $R$. solani.

\begin{tabular}{|l|l|l|l|}
\hline Isolates & $\begin{array}{l}\text { Time taken for initiation of } \\
\text { sclerotial formation (Days) }\end{array}$ & $\begin{array}{l}\text { Average sclerotia } \\
\text { diameter }(\mathrm{mm})\end{array}$ & $\begin{array}{l}\text { No. of sclerotia per } \\
\text { Petridish }\end{array}$ \\
\hline RS-1 & 4 & 1.24 & Excellent \\
\hline RS-2 & 5 & 1.21 & Good \\
\hline RS-3 & 3 & 2.38 & Excellent \\
\hline RS-4 & 4 & 1.65 & Very good \\
\hline RS-5 & 5 & 1.75 & Excellent \\
\hline RS-6 & 5 & 1.97 & Excellent \\
\hline RS-7 & 5 & 2.31 & Very good \\
\hline RS-8 & 5 & 1.75 & Good \\
\hline RS-9 & 5 & 2.21 & Very good \\
\hline RS-10 & 6 & 1.59 & Excellent \\
\hline RS-11 & 3 & 1.73 & Excellent \\
\hline RS-12 & 5 & 1.79 & Good \\
\hline RS-13 & 4 & 1.81 & Very good \\
\hline RS-14 & 5 & 2.01 & Excellent \\
\hline RS-15 & 4 & 2.12 & Excellent \\
\hline RS-16 & 5 & 1.46 & Good \\
\hline RS-17 & 4 & 2.94 & Very good \\
\hline RS-18 & 5 & 1.86 & Good \\
\hline RS-19 & 4 & 1.54 & Good \\
\hline RS-20 & 5 & 1.90 & Excellent \\
\hline RS-21 & 6 & 1.80 & Excellent \\
\hline RS-22 & 5 & 1.87 & Excellent \\
\hline RS- 23 & 5 & 2.18 & Very good \\
\hline RS-24 & - & 1.90 & \\
\hline RS-25 & 6 & 0.036 & \\
\hline CD(P=0.05) & & & \\
\hline & & - & \\
\hline
\end{tabular}

Table 4: Sclerotial characteristics of different isolates of $R$. solani.
(RS-1, RS-2, RS-5, RS-7, RS-9, RS-11, RS-13, RS-20 and RS-22). Second group included those isolates where sclerotia formed at the surface of the mycelium (RS-4, RS-6, RS-8, RS-12, RS-15, RS-16, RS-17, RS-18 RS-19, RS-21, RS-23 and RS-25). The isolates, RS-3, RS-8, RS-10, RS-14 and RS-18 had sclerotia embedded in the fungal mycelium itself.

Manner of sclerotia formation within the petridish: Based on number of sclerotium formed in the Petri dishes isolates of Rhizoctonia Solani were classified into three groups (Table 5). Sclerotium formed in the central ring was placed into group-1, which consisted of eight isolates (RS-3, RS-6, RS-9, RS-13, RS-15, RS-17, RS-21, and RS-22). Nine isolates (RS-2, RS-5, RS-10, RS-11, RS-12, RS-18, RS-23 and RS-25) were those, where sclerotium were formed in the peripheral manner and classified into group-2. Those isolates where sclerotium were formed scattered in the petridish i.e., neither peripheral nor central were placed into a separate groups-3 which included seven isolates (RS-1, RS-4, RS-7, RS-8, RS-14, RS-19 and RS-20).

\section{Time taken for sclerotia formation}

All isolates showed great variation in the time taken for initiation of sclerotia formation also whichranged from 3 to 6days (Table 4).Two isolates (RS-3, and RS-11) took 3 days for initiation of sclerotia formation, six isolates (RS-1, RS-4, RS-13, RS-15, RS-17 and RS-19) took 4days for initiation of sclerotia formation, thirteen isolates (RS-2, RS-5,RS-6, RS-7, RS-8,RS-9, RS-12, RS-14, RS-16, RS-18, RS-20, RS-22 and RS-23) took 5days for initiation of sclerotia formation and three isolates (RS-10, RS-21 and RS-25) took 6days for initiation of sclerotia formation.

\section{Molecular variability of $\boldsymbol{R}$. Solani isolates}

DNA amplification using RAPD: Among 25 RAPD primers, only 
Citation: Singh R, Murti S, Mehilalm, Tomer A, Prasad D (2015) Virulence Diversity in Rhizoctonia Solani Causing Sheath Blight in Rice. J Plant Pathol Microb 6: 296. doi:10.4172/2157-7471.1000296

Page 5 of 8

\begin{tabular}{|c|c|c|c|c|c|c|c|c|c|}
\hline \multirow{3}{*}{$\begin{array}{l}\text { Isolates } \\
\text { RS-1 }\end{array}$} & \multicolumn{3}{|c|}{ Manner of sclerotia Formation. } & \multirow{2}{*}{\multicolumn{3}{|c|}{\begin{tabular}{|l} 
Location of sclerotia \\
Arial Surface Embedded
\end{tabular}}} & \multicolumn{2}{|c|}{ Texture of sclerotia } & \multirow{3}{*}{$\begin{array}{l}\text { Colour of sclerotia } \\
\text { Light brown }\end{array}$} \\
\hline & \multicolumn{3}{|c|}{ Central Peripheral Scattered } & & & & \multirow{2}{*}{$\begin{array}{l}\text { Smooth } \\
+\end{array}$} & \multirow{2}{*}{$\begin{array}{l}\text { Rough } \\
\text { - }\end{array}$} & \\
\hline & - & - & + & + & + & - & & & \\
\hline RS-2 & - & + & - & + & - & - & + & - & Dark yellowih brown \\
\hline RS-3 & + & - & + & - & - & + & + & - & Light brown \\
\hline RS-4 & - & - & + & - & + & - & - & + & Dark brown \\
\hline RS-5 & - & + & - & + & - & - & - & + & Dark yellowish brown \\
\hline RS-6 & + & - & + & - & + & - & - & + & Light brown \\
\hline RS-7 & - & - & + & + & - & - & - & + & Dark brown \\
\hline RS-8 & - & - & + & - & + & + & + & - & Olive brown \\
\hline RS-9 & + & - & - & + & - & - & - & + & Dark brown \\
\hline RS-10 & - & + & - & - & - & + & + & - & Olive brown \\
\hline RS-11 & - & + & - & + & - & - & - & + & Dark brown \\
\hline RS-12 & - & + & - & - & + & - & + & - & Olive brown \\
\hline RS-13 & + & + & - & + & - & - & - & + & Dark yellowish brown \\
\hline RS-14 & - & - & + & - & - & + & + & + & Olive brown \\
\hline RS-15 & + & + & - & - & + & - & - & + & Olive brown \\
\hline RS-16 & - & + & - & - & + & - & + & - & Dark yellowish brown \\
\hline RS-17 & + & - & + & - & + & - & - & + & Dark brown \\
\hline RS-18 & - & + & - & - & + & + & - & + & Dark brown \\
\hline RS-19 & - & - & + & - & + & - & - & + & Dark yellowish brown \\
\hline RS-20 & - & - & + & + & - & - & - & + & Olive brown \\
\hline RS-21 & + & + & - & - & + & - & - & + & Dark yellowish brown \\
\hline RS-22 & + & + & - & + & - & - & + & - & Olive brown \\
\hline RS- 23 & - & + & - & - & + & - & + & - & Dark brown \\
\hline RS-24 & - & - & - & - & - & - & - & - & No formation of sclerotia \\
\hline RS-25 & - & + & - & - & + & - & - & + & Dark brown \\
\hline
\end{tabular}

$+=$ Present; - =Abesent.

Table 5: Formation, location, texture and colour of sclerotia of different isolates of $R$. solani.

\begin{tabular}{|c|c|c|c|c|c|}
\hline S.No. & Primers & $\begin{array}{l}\text { Total no. } \\
\text { of bands }\end{array}$ & $\begin{array}{l}\text { No. of polymorphic } \\
\text { bands }\end{array}$ & $\begin{array}{l}\text { No. of monomer- } \\
\text { phic bands }\end{array}$ & $\begin{array}{l}\text { Per cent } \\
\text { Polymorphism }\end{array}$ \\
\hline 1. & OPA 19 & 6 & 6 & 0 & 100 \\
\hline 2. & OPU 6 & 3 & 3 & 0 & 100 \\
\hline 3. & OPV 12 & 5 & 5 & 0 & 100 \\
\hline 4. & OPV 20 & 5 & 5 & 0 & 100 \\
\hline 5. & OPW 13 & 7 & 7 & 0 & 100 \\
\hline 6. & OPA 02 & 6 & 6 & 0 & 100 \\
\hline 7. & OPA 04 & 7 & 7 & 0 & 100 \\
\hline 8. & OPN 20 & 4 & 4 & 0 & 100 \\
\hline 9. & OPA 01 & 5 & 5 & 0 & 100 \\
\hline 10. & OPA 10 & 4 & 4 & 0 & 100 \\
\hline 11. & OPA 09 & 4 & 4 & 0 & 100 \\
\hline 12. & OPA 20 & 6 & 6 & 0 & 100 \\
\hline 13. & OPB 01 & 3 & 3 & 0 & 100 \\
\hline 14. & UBC 310 & 2 & 2 & 0 & 100 \\
\hline 15. & UBC 203 & 3 & 3 & 0 & 100 \\
\hline 16. & UPC248 & 3 & 3 & 0 & 100 \\
\hline 17. & OPB08 & 2 & 2 & 0 & 100 \\
\hline 18. & UBC373 & 5 & 4 & 1 & 80 \\
\hline 19 & OPU-14 & 0 & 0 & 0 & 0 \\
\hline 20 & UBC-310 & 0 & 0 & 0 & 0 \\
\hline 21 & OPU-02 & 0 & 0 & 0 & 0 \\
\hline 22 & OPW-13 & 0 & 0 & 0 & 0 \\
\hline 23 & UBC-338 & 0 & 0 & 0 & 0 \\
\hline 24 & UBC-374 & 0 & 0 & 0 & 0 \\
\hline 25 & UBC-248 & 0 & 0 & 0 & 0 \\
\hline \multicolumn{2}{|l|}{ Total } & 80 & 79 & 1 & \\
\hline
\end{tabular}

Table 6: Primer sequence, number of polymorphic and monomorphic bands present polymorphism.
18 resulted in the PCR products and rest of the 7 couldn't resulted in any PCR product. Out of 18 primers, resulting in PCR products, 17 primers gave polymorphic bands whereas one primer i.e. UBC-373 resulted in one monomorphic bands also.

Number of alleles in RAPD: During this experimentation, a total of 80 alleles were detected among 25 isolates of $R$. Solani. The number of alleles per locus varied from 1 to 7. (Table 4.6). The highest number of alleles were observed due to primer OPW 13 and OPA -04 (seven alleles) followed by OPA-02, OPA-19 and OPA- 20 (six alleles), OPV12 (five alleles), OPV- 20 (five alleles), OPA-01 (five alleles), OPN-20 (four alleles), OPA-10 (four alleles), OPA-09 (four alleles), OPU-6 (three alleles), OPB-01 (three alleles), UBC-203 (three alleles), UPC248(three alleles), UBC-310 (two alleles) and OPB-08 (two alleles). This provides the summarized data regarding the number of unique alleles and their distribution in various isolates. There was only 01 monomorphic band, which was present in related primer UBC-373

Polymorphism in RAPD primers: The total number of bands obtained were 80 , of which 79 bands were polymorphic and one was monomorphic, of which 17 were $100 \%$ polymorphic, with an average of 20.25 bands per primer, the number of polymorphic allele ranged from 1 to 7 and $100 \%$ polymorphism were obtained in the case of 17 primers and remaining 1 primer i.e.UBC373 did not give $100 \%$ polymorphism rather this could resulted in $80 \%$ polymorphism.

Similarity Vs dissimilarity analysis for RAPD primers: The cluster denogram revealed that all the 25 isolates of $R$. Solani can be grouped into two major clusters at a cut off similarity coefficient level 0.53 (Figure 1). Among these, cluster Ist was having only one isolates i.e. RS-16, whereas the cluster IInd was largest with 24 isolates. The IInd cluster having 24 isolates was further sub-divided into two groups at a 
similarity coefficient level of 0.57 . Among these two groups the group I included 7 isolates viz. RS-1, RS-3, RS-14, RS-25, RS-5, RS-9 and RS18 at a similarity coefficient level of 0.65 . Group IInd was consisted of remaining 17 isolates at a similarity coefficient 0.57 . The group Ist was again divided into two sub-group at a similarity coefficient 0.65 of which the isolated RS-1 was alone in one sub-group and remaining 6 were in other sub-group. These remaining 6 isolates were again subdivided into two groups at a similarity coefficient 0.71 wherethe isolate RS-18 was alone in one sub-group and remaining 5 isolates were in another sub-group. These 5 isolates were further sub-divided into two sub-groups at a similarity coefficient of 0.76 . Among these 5 isolates, the RS-9 \& RS-5 were in one sub-group \& remaining 3 isolates were in other sub-group. These remaining 3 isolates were again divided into two groups at a similarity coefficient 0.80 into two groups where RS-3 was alone in one group \& RS-14 \& RS-25 were in another sub-group with $86 \%$ level of similarity (Table 7 ).

The group two of IInd cluster, which consisted of 17 isolates, was further sub-divided into two groups at a similarity coefficient of 0.59 . Out of these, there was only one isolate i.e. RS-24 into one group and remaining 16 isolates of IInd group where reassigned to two groups at a similarity coefficient of around 0.65 . Between these two groups the isolates RS-20, RS-21, RS-22 and RS-23 were in one group with a similarity coefficient 0.85 . Whereas remaining 12 isolates were in another group with a similarity coefficient level of around 0.67. These 12 isolates were reassigned to two groups with a similarity coefficient 0.67 . Out of these two groups, in one group, there was 3 isolate i.e. RS-4, RS-15 and RS-19 with a similarity coefficient of 0.71 and in another group, remaining 9 isolates were placed with a similar similarity coefficient of 0.71 . These 9 isolates were again reassigned to two groups having 3 isolates i.e. RS-6, RS-7, and RS- 8 in one group with similarity coefficient of 0.75 and remaining 6 isolates in another group with similarity coefficient of 0.76 . The highest level of similarity coefficient i.e. 0.94 was observed between the isolates RS-11 and RS-12 both belonging to Uttar Pradesh followed by 0.92 between RS-20 and RS-21 these also belongs to Uttar Pradesh. The isolates RS-16, which belong to, Uttar Pradesh was found to highly distantly relate to isolate RS-1, which belongs to Punjab.

\section{Discussion}

From the experimental results, it is quite evident that all the 25 isolates of $R$. Solani were highly different from each other with respect to all the characters examined viz. color, growth, and texture of mycelium, number, size and color of sclerotium and also with respect to their genetic materials. Cultural and morphological characteristics in any living organism are governed and controlled by genetic and environmental factors. These characteristics also determine the virulence and aggressiveness of the pathogen. Variability is a common phenomenon occurring in plants and in the pathogen as well.Earlier also Rhizoctonia Solani has been thoroughly studied for variation in its different aspects and has shown great variability in its cultural, morphological,physiological and pathogenic charectaristics. Singh et al. [11] studied variability among 46 isolates from hil areas (Uttrakhand) and plain areas of U.P. in India. They analyzed intra-field variability in $R$. Solani through RAPD fingerprinting and found high variability among them. Neerajaet al. [12] observed 18 isolates of $R$. Solani from different geographic location of India for RAPD analysis. The similarity values of RAPD profile ranged from 0.41 to 0.85 with an average of 0.66 among all the isolates. Lal and Kandhari [1] determined the pathogenic variability of twenty five isolates of Rhizoctonia Solania causing sheath blight of rice on a highly susceptible cultivar,Pusa Basmati-1 in the
Phytotron Facility at IARI, New Delhi. The isolates were charectarized into two virulent groups. Thirteen isolates (RS-1, RS-2,RS-3, RS-4, RS-7, RS-9, RS-10, RS-12, RS-13, RS-14, RS-19, RS-22, RS-23, RS-25 ) showed 7.0 disease score, and were grouped as moderately virulent, whereas twelve isolates, belonging to the virulent group (RS-3, RS-5, RS-6, RS-8, RS-11, RS-15, RS-16, RS-17, RS-18, RS-20, RS- 21, RS-24) had disease score of 9.0. Maximum relative lesion height (75.96\%) and disease severity (59.16\%) was observed in isolate RS-18 (Haryana) whereas isolate RS-25 (New Delhi) caused minimum relative lesion height (55.81\%) and disease severity (13.35\%). All the isolates showed maximum relative height at tillering stage but subsequently decreased at panicle initiation stage. Although in present studies the pathogenic aspects were not investigated but the cultural and morphological variations noticed are of great academic significance provided they are properly correlated with virulence, which may be the objectives of some other studies.

\section{Molecular virulence diversity of Rhizoctonia Solani:}

Based on cluster dendogram prepared according to PCR products obtained in different isolates and due to different primers, all the 25 isolates of $R$. Solani have been grouped into two major clusters at a similarity coefficient of 0.53 . Between these two clusters, the cluster Ist was having only one isolates i.e. RS-16, whereas the cluster IInd was largest with 24 isolates. The IInd cluster having 24 isolates was further sub-divided into two groups with a similarity coefficient of 0.57 . Between these two groups, the group I included 7 isolates viz. RS-1, RS-3, RS-14, RS-25, RS-5, RS-9 and RS- 18 at a similarity coefficient of 0.65 . Group IInd was consisted of remaining 17 isolates at a similarity coefficient 0.57 . The group Ist was again divided into two sub-group at a similarity coefficient 0.65 of which the isolated RS- 1 was alone in one sub-group and remaining 6 were in other sub-group. These remaining 6 isolates were again sub-divided into two groups at a similarity coefficient 0.71 . Where the isolate RS-18 was alone in one sub-group and remaining 5 isolates were in another sub-group. These 5 isolates were further sub-divided into two sub-groups at a similarity coefficient of 0.76 . Among these 5 isolates the RS- 9 \& RS- 5 were in one sub-group \& remaining 3 isolates were in other sub-group. These remaining 3 isolates were again divided into two groups at a similarity coefficient 0.80 into two groups, where RS-3 was alone in one group \& RS-14 \& RS-25 were in another sub-group with $86 \%$ level of similarity.

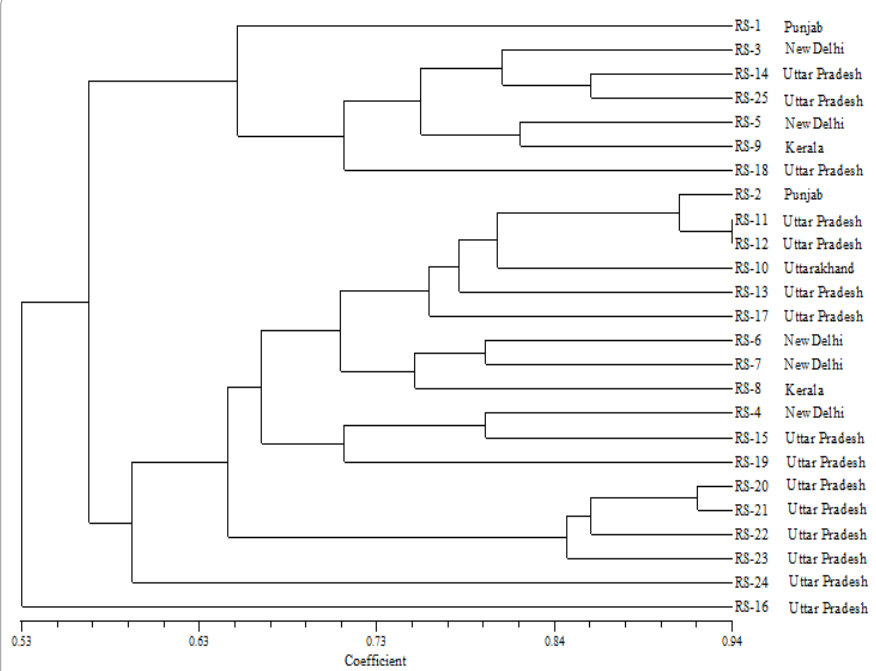

Figure 1: Dendogramdecepting Genetic diversity of $R$. solani. 


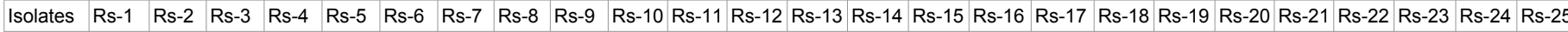

Rs-1 1.000

\begin{tabular}{l|l|l|l|l}
\hline Rs-2 & 0.571 & 1.000
\end{tabular}

\begin{tabular}{l|l|l|l|l}
\hline Rs-3 & 0.612 & 0.633 & 1.000
\end{tabular}

\begin{tabular}{l|l|l|l|l|l|l|l|l|l|l|l|}
\hline Rs-4 & 0.673 & 0.653 & 0.735 & 1.000
\end{tabular}

\begin{tabular}{l|l|l|l|l|l|l|l|l|l|l|l|l|l}
\hline Rs-5 & 0.714 & 0.490 & 0.735 & 0.592 & 1.000 \\
\hline
\end{tabular}

\begin{tabular}{l|l|l|l|l|l|l|l|l|l} 
Rs-6 & 0.490 & 0.755 & 0.714 & 0.694 & 0.490 & 1.000
\end{tabular}

\begin{tabular}{l|l|l|l|l|l|l|l|l|}
\hline Rs-7 & 0.408 & 0.714 & 0.592 & 0.653 & 0.449 & 0.796 & 1.000
\end{tabular}

\begin{tabular}{l|l|l|l|l|l|l|l|l|l|}
\hline Rs-8 & 0.531 & 0.633 & 0.633 & 0.694 & 0.408 & 0.796 & 0.714 & 1.000
\end{tabular}

\begin{tabular}{l|l|l|l|l|l|l|l|l|l|l|l}
\hline Rs-9 & 0.735 & 0.510 & 0.755 & 0.694 & 0.816 & 0.510 & 0.388 & 0.469 & 1.000
\end{tabular}

\begin{tabular}{|l|l|l|l|l|l|l|l|l|l|l|}
\hline Rs-10 & 0.531 & 0.796 & 0.592 & 0.735 & 0.612 & 0.673 & 0.714 & 0.551 & 0.510 & 1.000
\end{tabular}

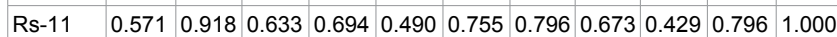

\begin{tabular}{|l|l|l|l|l|l|l|l|l|l|l|l|l|}
\hline Rs-12 & 0.551 & 0.898 & 0.653 & 0.714 & 0.510 & 0.776 & 0.816 & 0.694 & 0.449 & 0.816 & 0.939 & 1.000
\end{tabular}

\begin{tabular}{l|l|l|l|l|l|l|l|l|l|l|l|l|l|l}
\hline Rs-13 & 0.469 & 0.776 & 0.571 & 0.633 & 0.510 & 0.776 & 0.776 & 0.612 & 0.408 & 0.776 & 0.816 & 0.755 & 1.000
\end{tabular}

\begin{tabular}{|l|l|l|l|l|l|l|l|l|l|l|l|l|l|l|}
\hline Rs-14 & 0.633 & 0.571 & 0.816 & 0.673 & 0.796 & 0.571 & 0.490 & 0.490 & 0.776 & 0.612 & 0.531 & 0.551 & 0.551 & 1.000 \\
\hline
\end{tabular}

\begin{tabular}{|l|l|l|l|l|l|l|l|l|l|l|l|l|l|l|l|l|l}
\hline Rs-15 & 0.633 & 0.653 & 0.694 & 0.796 & 0.673 & 0.612 & 0.612 & 0.612 & 0.694 & 0.735 & 0.653 & 0.673 & 0.633 & 0.755 & 1.000
\end{tabular}

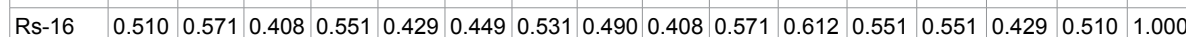

\begin{tabular}{|l|l|l|l|l|l|l|l|l|l|l|l|l|l|l|l|l|l|l|l|l}
\hline Rs-17 & 0.612 & 0.755 & 0.755 & 0.735 & 0.653 & 0.714 & 0.714 & 0.673 & 0.592 & 0.755 & 0.796 & 0.776 & 0.735 & 0.694 & 0.694 & 0.531 & 1.000 \\
\hline
\end{tabular}

\begin{tabular}{|l|l|l|l|l|l|l|l|l|l|l|l|l|l|l|l|l|l|l|l|l|l|l} 
Rs-18 & 0.653 & 0.673 & 0.796 & 0.653 & 0.694 & 0.673 & 0.551 & 0.592 & 0.714 & 0.551 & 0.633 & 0.653 & 0.531 & 0.694 & 0.612 & 0.490 & 0.755 & 1.000
\end{tabular}

\begin{tabular}{|l|l|l|l|l|l|l|l|l|l|l|l|l|l|l|l|l|l|l|l|l|l|l}
\hline Rs-19 & 0.510 & 0.694 & 0.612 & 0.714 & 0.551 & 0.571 & 0.653 & 0.490 & 0.612 & 0.735 & 0.694 & 0.714 & 0.633 & 0.592 & 0.714 & 0.551 & 0.735 & 0.612 & 1.000 \\
\hline
\end{tabular}

\begin{tabular}{|l|l|l|l|l|l|l|l|l|l|l|l|l|l|l|l|l|l|l|l|l|l|l}
\hline Rs-20 & 0.490 & 0.714 & 0.592 & 0.653 & 0.531 & 0.633 & 0.551 & 0.510 & 0.510 & 0.714 & 0.714 & 0.694 & 0.653 & 0.531 & 0.612 & 0.612 & 0.673 & 0.591 & 0.734 & 1.000 \\
\hline
\end{tabular}

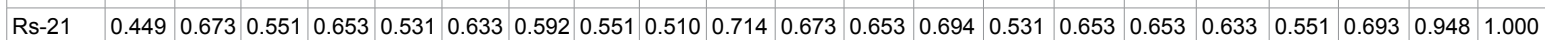

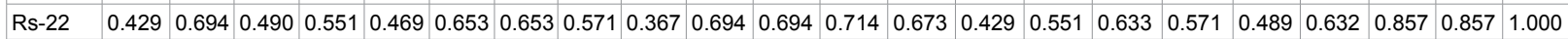

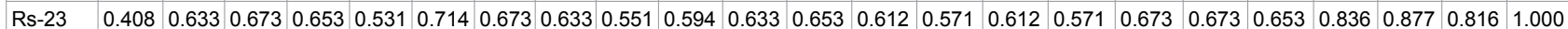

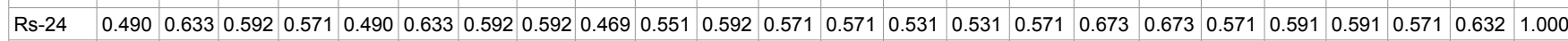

\begin{tabular}{|l|l|l|l|l|l|l|l|l|l|l|l|l|l|l|l|l|l|l|l|l|l|l|l|l|l} 
Rs-25 & 0.571 & 0.592 & 0.796 & 0.653 & 0.776 & 0.551 & 0.469 & 0.510 & 0.714 & 0.592 & 0.551 & 0.531 & 0.571 & 0.857 & 0.735 & 0.490 & 0.673 & 0.673 & 0.612 & 0.673 & 0.632 & 0.571 & 0.673 & 0.551 & 1.000
\end{tabular}

Table 7: Jaccard's similarity coefficient of 25 isolates of Rhizctonia solani based on DNA bands characters.

The group two of IInd cluster, which consisted of 17 isolates, was further sub-divided into two groups at a similarity coefficient of 0.59 . Out of these, there was only one isolate i.e. RS-24 into one group and remaining 16 isolates of IInd group where reassigned to two groups at a similarity coefficient of around 0.65 . Between these two groups, the isolates RS-20, RS-21, RS-22 and RS-23 were in one group with a similarity coefficient 0.85 . Whereas remaining 12 isolates were in another group with a similarity coefficient level of around 0.67 . These 12 isolates where reassigned to two groups with a similarity coefficient 0.67 . Out of these two groups, in one group, there was 3 isolate i.e. RS4, RS-15 and RS-19 with a similarity coefficient of 0.71 and in another group remaining 9 isolates were placed with a similar similarity coefficient of 0.71 . These 9 isolates were again reassigned to two groups having 3 isolates i.e. RS- 6 , RS-7, and RS- 8 in one group with similarity coefficient of 0.75 and remaining 6 in another group with similarity coefficient of 0.76 . The highest level of similarity coefficient i.e. 0.94 was observed between the isolates RS-11 and RS-12 both belonging to Uttar Pradesh followed by 0.92 between RS-20 and RS- 21 these also belong to Uttar Pradesh. The isolates RS-16, which belong to Uttar Pradesh, were found to highly distantly relate to isolate RS-1, which belongs to Punjab.

More recently, the use of molecular markers has given a boost to analysis of accurate variation among various isolates of the pathogen. Random Amplified Polymorphic DNA (RAPD) technique has been used consistently to determine the genetic variation and subsequently correlating it with the variation in the pattern of the pathogen. Random polymorphic PCR approaches are being increasingly used to generate molecular marker, which are useful for taxonomic characterization of fungal populations. The main advantage of these approaches is that, previous knowledge of DNA sequence is not required, so that any random primer can be tested to amplify any fungal DNA. RAPD primers are chosen empirically and tested experimentally to find RAPD banding patterns, which are polymorphic between the isolate, studied. The RAPD method successfully used to differentiate and to identify fungi at the transpacific level [11,13-15] and interspecific level [16]. RAPD-PCR analyzes loci with few each primer. Differences between isolates from different areas are therefore more easily detected. The RAPD technique has been used to detect genetic variation amongst strains / isolates with in a species $[2,17]$.

It can be concluded that there is great genetic diversity in the population of $R$. Solani causing sheath blight in rice or infecting other hosts. Genetic diversity in the pathogen has been clearly visible in its morphological features like, color, texture,growth pattern and growth rate of the mycelium along with color, size and number of sclerotium. There is all possibility that genetic diversity existing in R.Solani population may be one of the main reason that why sheath blight disease has become a problem worldwide and very difficult to manage through host resistance [18].

\section{References}

1. Lal M, Janki K (2009) Cultural and Morphology variability in Rhizoctonia solani isolates causing Sheath Blight of Rice. J MycoPIthol 39: 7-81

2. Boyette ML, Carris LM (1997) Molecular relationship among varieties of Tilletiafusca (T. bromi) complex and related species. Mycol Res 99: 1119-1127.

3. Kotasthane AS, Agrawal T, Shalini, Saluja M (2004) A specialized approach for managing on unspecialized fungus causing sheath blight disease in rice International Symposium an Rainfed Rice Ecosystems: Perspective and Potential, IndraGhandi Agri Univ, Raipur, Chhattisgarh, India. pp: 40.

4. Eechhout E, Rush MC, Black well M (1991) Effect of rate and timing of fungicide applications on incidence and severity of sheath blight and grain yield of rice. Plant Dis 75: 1254-1261.

5. Vilgalys R, Cubeta MA (1994) Molecular systematic and population biology of Rhizoctonia. Annu Rev Phytopathol 32: 135-155.

6. Burpee LL, Sander PL, Sherwood RT (1980) Anastomosis group amongislates of Ceratobasdium cornigerum (Bourd) Rogers and related fungi. Mycologia 72: 689-701.

7. Murray MG, Thompson WF (1980) Rapid isolation of high molecular weight plant DNA. Nucleic Acid Res 8: 4321-4325. 
Citation: Singh R, Murti S, Mehilalm, Tomer A, Prasad D (2015) Virulence Diversity in Rhizoctonia Solani Causing Sheath Blight in Rice. J Plant Pathol Microb 6: 296. doi:10.4172/2157-7471.1000296

8. Pascual CB, Toda T, Raymondo AD, Hyakumachi M (2002) Characterization by convectional techniques and PCR of Rhyzoctonia solani isolates causing banded leaf blight in Maize. Plant Pathol 49: 108-118.

9. Nei M, Li WH (1979) Mathematical model for studying genetic variation in terms of restriction endonucleases. Proc Natl Acad Sci USA 76: 5269-5273.

10. Rohif FJ (2000) Numerical Taxonomy and Multivariate Analysis System. Version 2.11a.Exeter software Setauket, New York.

11. Singh V, Singh US, Singh KP, Singh M, Kumar A (2002) Genetic diversity of Rhizoctonia solani Isolates from Rice:Differentiation by Morphological characteristics, Pathogenicity Anastomosis Behaviour and RAPD Fingerprinting. J Myco PI Pathol 32: 332-334.

12. Neeraja CN, Vijayabhanu N, Shenoy VV, Reddy CS, Sharma NP (2002) RAPD analysis of Indian isolates of rice sheath blight fungus Rhizoctonia solani. J Plant Biochemistry \& Biotechnology 11: 43-48.

13. Guthrie PAI, Magill CW, Frederkisen RA, Odavory GN (1992) Random amplified polymorphic DNA mrkers: asystem for identifying and differentiating isolates of Clletotrichum graminicola. Phytopathology 82: 832-835.
14. Assigetse KB, Fernandez D, Dubois MP, Geiger JP (1994) Differentiation and of Fusarium oxysporum $\mathrm{f}$. sp vasinfectum races on cotton by random amplified polymorphic DNA (RAPD) analysis. Phytopathology 84: 622-626.

15. Nicholson P, Rezanoor HN (1994) The use of random amplification polymorphic DNA to identify pathotype and detected the variation in Pseudocerocosporella herpotrichoides. Mycol Res 98: 13-21.

16. Lehmann PF, Lin D, Lasker BA (1992) Genotypic identification and characterization of species and strains within the genus Candida by using random amplified polymorphic DNA. J Clin Microbiol 30: 3249-3254.

17. Cooke DEL, Kennedy DM, Guey DC, Russell J, Unkley SE, et al. (1996) Relatedness of group in species of Phytophthora as assessed by Random amplified polymorphic DNA (RAPD) and sequences of ribosomal DNA. Mycol Res 100: 297-303.

18. Sharma D, Thrimurty VS (2005) Protection and therapeutant ability of validamycin against sheath blight of rice. Environment and Ecology 23: 933994. 